\title{
Üniversite Öğrencilerinde Öğrenim Türü ve Cinsiyetin Gece Yeme Sendromuna Etkisi
}

\author{
Tuba Tekin $^{1} \odot$, Neslihan $0 \ddot{n e r}{ }^{2} \odot$
}

'Sivas Cumhuriyet Üniversitesi Sağlık Bilimleri Fakültesi, Beslenme ve Diyetetik Bölümü, Sivas, Türkiye 2Erciyes Üniversitesi Sağılı Bilimleri Fakültesi Beslenme ve Diyetetik Bölümü, Kayseri, Türkiye

Tuba Tekin, Arş. Gör. Neslihan Öner, Dr. Öğr. Üyesi

Bu çalışma 3-5 Mayıs 2018 tarihleri arasında Nevşsehir'de düzenlenen 1. Uluslararası Spor, Antropoloji, Beslenme, Anatomi ve Radyoloji Kongresi'nde (SANAR 2018) sözel bildiri olarak sunulmuştur.

Iletişim:

Arş. Gör. Tuba Tekin

Sivas Cumhuriyet Üniversitesi Sağık Bilimleri Fakültesi, Beslenme ve Diyetetik Bölümü, Sivas, Türkiye

Tel: +90 5549622957

E-Posta: tuba.tekin38@gmail.com

Gönderilme Tarihi : 06 Eylül 2018

Revizyon Tarihi : : 05 Ekim 2018

Kabul Tarihi : $\quad 10$ Ekim 2018
ÖZET

Amaç: Bu çalışma Erciyes Üniversitesi öğrencilerinde öğrenim türü ve cinsiyetin gece yeme sendromuna (GYS) etkisini belirlemek amacıyla planlanmıştır.

Çalışma Planı: Çalışmanın verileri Aralık 2017 ve Mart 2018 ayları arasında Gece Yeme Anketi kullanılarak toplanmışıı. Örneklem büyüklüğü tabakalı sistematik örnekleme yöntemi kullanılarak hesaplanmıştır. Erciyes Üniversitesi Sosyal ve Beşeri Bilimler Etik Kurulu'ndan çaIışmanın yürütülmesi için gerekli izin alınmıştır (28/11/2017-59). Çalışmanın sonucunu etkileyebileceğinden dolayı Tıp ve Sağık Bilimleri ile ilgili fakülteler dâhil edilmemiștir. Normal dağılıma uygunluk Shapiro-Wilk testi ile değerlendirilmiștir. Nicel veriler aritmetik ortalama $\left(x^{-}\right)$standart sapma $( \pm S S)$, nitel veriler sayı $(n)$ ve yüzde $(\%)$ olarak gösterilmiştir. Grupların nicel değişkenlerinin karşılaştırımasında Student-t testi, nitel değişkenlerinin karșslaștırımasında ise ki-kare testi kullanııııștır.

Bulgular: Çalışmaya toplam 1024 öğrenci dahil edilmiştir. Öğrencilerin \%54,3'ü erkek, \%45,7'si kadın olup, \%60,4'ü birinci öğrenim ve \%39,6'sı ikinci öğrenim olarak eğitim almaktadır. Sigara kullanımının görülme sıklığı $\% 32$ iken, alkol kullanımının görülme sıklığ \%19,3'tür. Öğrencilerin \%66's'snda GYS görüldüğü ve Gece Yeme Anketinden alınan toplam puanın 26,41 4 4,42 olduğu bulunmuştur. Cinsiyet ve öğrenim türü ile GYS görülme durumu arasında anlamlı bir ilişkiye rastlanmamıştır. Benzer şekilde, yaș, ağırlık, boy ve beden kütle indeksi (BKi) ile GYS görülme durumu arasında anlamlı bir ilişkiye rastlanmamıştır. Sigara kullanan öğrencilerde GYS görülme sıkı̆̆ı sigara kullanmayan öğrencilerde GYS görülme sıklı̆ına göre anlamlı olarak daha fazladır $(p=0,009)$. Ancak, alkol kullanımı ile GYS görülme sıklığı arasında anlamlı bir ilişki bulunmamıştır.

Sonuç: Üniversite öğrencileri arasında gece yeme sendromu görülme sıklığıın oldukça yüksek olduğu ortaya konmuştur. Bu nedenle üniversite öğrencileri arasında gece yeme sendromu gibi yeme bozukluklarının görülme sıklı̆ı saptanarak gerekli önlemler alınmalıdır.

Anahtar sözcükler: Beslenme, üniversite öğrencileri, yeme bozukluğu, gece yeme sendromu

\section{THE EFFECT OF EDUCATION TYPE AND GENDER ON NIGHT EATING SYNDROME IN UNIVERSITY STUDENTS}

\section{ABSTRACT}

Objective: This study was planned/aimed to determine the effect of education type and gender on night eating syndrome (NES) in Erciyes University students.

The work plan/Materials and methods: Data were collected between December 2017 and March 2018 using Night Eating Questionnaire (NEQ) and a general questionnaire. The sample size was calculated with a systematic sampling method. The study was approved by the Committee of Social and Human Sciences of Erciyes University (28/11/2017-59). The study did not include Medicine and Health Sciences that may affect the outcome of the study. Normality was evaluated with the Shapiro-Wilk test. Quantitative data were presented as arithmetic mean $\left(x^{-}\right)$, standard deviation $( \pm S S)$, qualitative data were represented as a number $(n)$ and percentage $(\%)$. The student $t$-test was used to compare quantitative variables of the groups, and the Chi-square test was used to compare qualitative variables.

Results: A total of 1024 students were included in the study. $54.3 \%$ of the students were male and $45.7 \%$ were female while $60.4 \%$ were daytime education and $39.6 \%$ were evening education. While the prevalence of smoking was $32 \%$, the prevalence of alcohol consumption was $19.3 \%$. It was found that NES was seen in $66 \%$ of the students and the total score of the Night Eating Questionnaire was $26.41 \pm 4.42$. No significant relation was found between gender or education type and presence of NES. Similarly, there was no significant relation between age, weight, height, and body mass index (BMI) and presence of NES. The prevalence of NES was significantly higher in smokers than non-smokers $(\mathrm{p}=0.009)$. However, there was no significant relation between alcohol using and the prevalence of NES.

Conclusion: The frequency of night eating syndrome among university students was found to be quite high. For this reason, the frequency of eating disorders such as night eating syndrome should be determined among university students and necessary precautions should be taken.

Keywords: Nutrition, university students, eating disorder, night eating syndrome 
B eslenme, açlık ve acıkma gibi biyolojik dürtüler uyanık olma hali ile ilişkilidir. Uyku durumu ve beslenme, açlık, acıkma arasındaki ilişki homeostatik ve sirkadiyen ritimler ile düzenlenmektedir. İnsanda yemek yeme ve uyku durumunun sirkadiyen ritmi birbirleri ile bağlantılı olup, senkronize olarak çalışmaktadır. Bu nedenle uyku durumunda yemek yenmemesine rağmen, enerji metabolizması kan glikoz düzeyinin düzenlenmesini iştah durumundaki değişikliklerle kontrol etmektedir. Uyku zamanında görülen anormal yeme davranışının farklı nedenleri bulunmaktadır (1). Gece yeme sendromu gibi yeme bozuklukları ise, obezitenin artması ile birlikte araştırılan ve ilgi çeken konular arasındadır.

Gece yeme sendromu (GYS) ilk olarak 1955 yılında Stunkard ve arkadaşları (2) tarafından tedaviye dirençli obez bireylerde görülen sabah iştahsızlığı, gece aşırı yeme ve uykusuzluk ile karakterize bir bozukluk olarak tanımlanmıştır. GYS, genellikle akşam yemeğinden sonra toplam günlük kalorinin en az $\% 25^{\prime}$ inin alınması veya haftada en az iki kez gece yemek yeme durumunun ortaya çıkması şeklinde tanımlanmaktadır (3). GYS, ilk tanımından itibaren resmi sınıflama sistemlerinde yeme bozukluğu olarak tanımlanmamıştır (4). Ancak GYS, 2013 yılında Ruhsal Bozuklukların Tanısal ve Sayımsal EI Kitabının beşinci baskısında (DSM-5) başka yerde sınıflandırılmayan beslenme ve yeme bozukluğu başlığı altında tanımlanmıştır (5).

Çalışmalar, GYS olan bireylerin akşam yemeğinden sonra kalorilerinin önemli bir kısmını yediklerini ve gece boyunca yemek yemeye kalktıklarını göstermiştir. GYS, sirkadiyen yeme modelinde gecikmeye neden olan ve uykuyu bozan bir yeme bozukluğudur. Gece yeme sendromunda yemek yeme ve uyuma sirkadiyen ritimleri ayrılmıştır. Bununla birlikte, uyku döngülerinin zamanlaması ve sabah uyanma zamanları faza uygundur, bu da gecikmiş yeme ritminin ikincil olarak uykuyu bozabileceğini düşündürmektedir (6). Gece yeme davranışına stres, uyku, açlıkla ilişkili hormonların neden olduğu biyolojik faktörler ve duygusal faktörler katkıda bulunmaktadır. Bu bireylerde akşam ve gece geç saatlerde yemek yeme hoşnutluktan ziyade gerginlik, suçluluk, utanma duygularına yol açmakta ve uyku problemlerine neden olmaktadır (4).

Epidemiyolojik olarak incelendiğinde genel popülasyonda GYS prevalansı yaklaşık olarak \%1,5 olarak saptanmıştır. Ağırlık kaybı için klinik olarak takip edilen hastaların \%6-14'ünde, bariatrik cerrahi için bekleyen hastaların \%8,9-42'sinde mevcut olduğu bulunmuştur (7-9). Psikiyatri hastalarında ise GYS prevelansı \%12 olarak bildirilmiştir (10). Tip 2 diyabetli yaşlı hastalarda GYS görülme sıklığı \%3,8, uyku apnesi olan bireylerde \%8,6 ve huzursuz bacak sendromu olan hastalarda \%17 olarak gözlenmiştir (11-13).

Gece yeme sendromu tanısı ilk olarak obez bireylere konmuştur; ancak obez olmayan bireylerde de görüldüğü bildirilmiştir (14). GYS ve cinsiyet arasındaki ilişkiyi inceleyen çalışmalar ise sınırıdır. Yapılan bir çalışmada normal ağırlıktaki bireylerde GYS görülme sıklığının her iki cinsiyette benzer olduğu bulunmuştur (1). Klinik ve epidemiyolojik çalışmalardan elde edilen veriler de, GYS ve cinsiyet arasında ilişki olmadığını göstermektedir (15).

Herhangi bir yeme bozukluğunun genç bireylerde görülme sıklığı ise \%4 olarak bildirilmektedir (16). Görülme sıkığı giderek artan yeme bozuklukları için yüksek riskli gruplar özellikle lise ve üniversite öğrencilerinden oluşmaktadır (17). Ülkemizde çeşitli popülasyonlarda GYS görülme sıklığını araştıran çalışmalar mevcuttur. Ancak literatürdeki çalışmalar incelendiğinde, üniversite öğrencileri arasında gece yeme sendromu görülme sıklığını ve cinsiyet ile gece yeme sendromu arasındaki ilişkiyi araştıran oldukça az sayıda çalışma bulunmaktadır. Bu nedenle araştırma grubu olarak üniversite öğrencileri seçilmiştir. Çalışmada üniversite öğrencileri arasında gece yeme sendromu görülme sıklığı ile cinsiyet ve öğretim türünün gece yeme sendromu üzerine olan etkisi araştırılmıştır.

\section{Çalışma planı}

Bu çalışmanın örneklemini Kayseri Erciyes Üniversitesi İktisadi ve İdari Bilimleri, Illahiyat, Eğitim, Illetişim, Fen, Edebiyat, Turizm, Havacılık ve Uzay Bilimleri ve Mühendislik Fakültesi birinci ve ikinci öğretimde okuyan öğrenciler oluşturmuştur. Veriler Aralık 2017 ve Mart 2018 ayları arasında toplanmıştır. Çalışma sonucunu etkileyebileceğinden dolayı, müfredatlarında beslenme eğitimi bulunan Tıp ve Sağlık Bilimleri ile ilgili fakülteler dâhil edilmemiştir. Örneklem büyüklüğü, Erciyes Üniversitesinde okuyan toplam öğrenci sayısı elde edilerek tabakalı sistematik örnekleme yöntemi kullanılarak hesaplanmıştır. Erciyes Üniversitesi Sosyal ve Beşeri Bilimler Etik Kurulu'ndan çalışmanın yürütülebilmesi için gerekli izinler alınmıştır (28/11/2017-59).

Öğrencilerin yaş, cinsiyet, boy, kilo, sigara ve alkol tüketim durumları gibi tanımlayıcı özellikleri anket formu yolu ile toplanmıştır. Gece yeme sendromu sıklığını 
belirlemek amacıyla Gece Yeme Anketi kullanılmıştır. Gece yeme anketi ilk olarak Allison ve arkadaşları (18) tarafından geliştirilmiştir. Gece yeme anketi Türkçe'ye uyarlanarak psikiyatrik hasta popülasyonunda geçerlilik güvenilirlik çalışması Atasoy ve arkadaşları (19) tarafından, anketin genel yetişkin popülasyonundaki iç güvenilirliği ise Peker ve arkadaşları (20) tarafından yapılmıştır. Gece yeme anketi 14 sorudan oluşmaktadır. Ankette ilk besin alımı, sabah iştah durumu, akşam ve gece yeme durumu, akşam yemeğinden sonra alınan besin miktarı, gece yeme davranışı üzerindeki kontrol, uykuya dalma güçlüğü, gece uyanarak yemek yeme sıklığı, gece yemek yeme durumundaki farkındalık ve duygu durum ile ilgili sorular bulunmaktadır. Gece uyanmayan veya gece atıştırması olmayan katılımcılar dokuzuncu sorudan sonra ankete devam etmemektedir. Gece uyanmaları olan katılımcılar 10-12. soruları, gece yeme durumu olan katılımcılar ise 13. ve 14. soruları cevaplamaktadır. Ankette bulunan sorular (7. soru hariç) beşli likert tipi ile 0-4 arasında puanlanmaktadır. 7. soru ile gün içindeki duygu durumundaki değişiklik sorgulanmakta olup, duygu durumunda değişiklik olmayanlar için 0 puan verilmektedir. Anketteki 1, 4 ve 14. sorular ise ters puanlanmaktadır. 13. soruda gece yemek yeme durumunun farkındalığı sorgulanmakta olup, puanlamaya dâhil edilmemektedir. Anketten toplam 0-52 arasında puan alınmaktadır. Ankette yer alan 15 . ve 16 . sorular ek soru olarak yer almaktadır ancak puanlamaya dâhil edilmemiştir. Gece yeme sendromu için 25 ve üzeri puanın kesim noktası olduğu belirtilmiştir (18).

Katılımcıların ağırlık ve boyları yöntemine uygun şekilde, esnemeyen standart mezura ve 0,1 kg duyarlı tartı ile ölçülmüştür. Elde edilen ağırlık ve boy ölçümü değerlerinden Beden Kütle İndeksi (BKi) [ağırlık (kg)/boy (m) ${ }^{2}$ ] formül ile hesaplanmıştır. Çalışmanın verilerinin değerlendirilmesinde SPSS 22,0 (Statistical Package for the Social Sciences, NY, USA) istatistik paket programı kullanılmıştır. Normal dağılıma uygunluk Shapiro-Wilk testi ile değerlendirilmiştir. Nicel veriler aritmetik ortalama $(\overline{\boldsymbol{x}})$, standart sapma ( \pm SS), nitel veriler sayı (n) ve yüzde (\%) olarak gösterilmiştir. Grupların nicel değişkenlerinin karşılaştırılmasında Student-t testi, nitel değişkenlerinin karşılaştırılmasında ise ki-kare testi kullanılmıştır.

\section{Bulgular}

Çalışmaya birinci ve ikinci öğretimde okuyan 1024 öğrenci dâhil edilmiştir. Örneklemin \%54,3'ünü erkek, $\% 45,7$ 'sini kız öğrenciler oluşturmuştur. Birinci öğretimde okuyan öğrenciler örneklemin $\% 60,4$ 'ünü, ikinci öğretimde okuyan öğrenciler ise \%39,6'sını oluşturmuştur. Çalışmanın örneklemi tabakalı örnekleme yöntemi ile hesaplanmış olup, çalışmaya en fazla öğrenci mühendislik fakültesinden, en az öğrenci ise turizm fakültesinden dâhil edilmiştir. Çalışmaya katılan öğrencilerin tanımlayıcı özellikleri ve fakültelere göre öğrenci dağılımları Tablo 1'de gösterilmiştir. Çalışmaya katılan öğrencilerin yaş ortalaması 21,23 $\pm 1,95$ yıl, ağırlık ortalaması $67,92 \pm 13,94 \mathrm{~kg}$, boy ortalaması $171,77 \pm 9,16 \mathrm{~cm}$, BKI ortalaması ise $22,86 \pm 3,40 \mathrm{~kg} / \mathrm{m}^{2}$ olarak saptanmıştır. Öğrencilerin yaş ve antropometrik ölçümlerinin ortalaması Tablo 2'de verilmiştir.

Tablo 1. Öğrencilerin tanımlayıcı özelliklerine göre dağılımları

\begin{tabular}{lcc} 
Tanımlayıcı özellikler & Sayı (n) & Yüzde (\%) \\
\hline Cinsiyet & 556 & 54,3 \\
Erkek & 468 & 45,7 \\
Kadın & & \\
Fakülte & 169 & 16,5 \\
İktisadi ve İdari Bilimleri Fakültesi & 82 & 8,0 \\
İlahiyat Fakültesi & 83 & 8,1 \\
Eğitim Fakültesi & 75 & 7,3 \\
İletişim Fakültesi & 40 & 3,9 \\
Fen Fakültesi & 178 & 17,4 \\
Edebiyat Fakültesi & 11 & 1,1 \\
Turizm Fakültesi & 20 & 2,0 \\
Havacılık ve Uzay Bilimleri Fakültesi & 366 & 35,7 \\
Mühendislik Fakültesi & & \\
Öğrenim türü & 618 & 60,4 \\
Birinci Öğretim & 406 & 39,6 \\
İkinci Öğretim & 1024 & 100,0 \\
Toplam &
\end{tabular}

Tablo 2. Öğrencilerin yaş ve antropometrik ölçümlerinin ortalamaları

\begin{tabular}{lcc} 
Yaş ve Antropometrik Ölçümler & Ortalama \pm SS & Min-Max \\
\hline Yaş (yıl) & $21,23 \pm 1,95$ & $18-36$ \\
Ağırlık (kg) & $67,92 \pm 13,94$ & $40-140$ \\
Boy (cm) & $171,77 \pm 9,16$ & $146-198$ \\
BKi $\left(\mathrm{kg} / \mathrm{m}^{2}\right)$ & $22,86 \pm 3,40$ & $15,17-41,66$
\end{tabular}

Çalışmaya katılan öğrencilerin sigara ve alkol tüketim durumları incelendiğinde; öğrencilerin \%32'sinin sigara kullandığı, \%19,3'ünün alkol tükettiği bulunmuştur. Sigara kullanan öğrencilerin \%76'sı her gün kullandığını, \%7,9'u gün aşırı, \%16,1'i çok seyrek kullandığını belirtmiştir. Alkol tüketen öğrenciler ise \%8'i her gün, \%14,5'i gün aşırı, $\% 77,5^{\prime}$ i seyrek tükettiklerini belirtmiştir (Tablo 3). 
Tablo 3. Öğrencilerin sigara ve alkol kullanma durumlarına göre dağ|lımları

\begin{tabular}{lcc} 
Sigara ve alkol kullanma durumu & Sayı (n) & Yüzde (\%) \\
\hline Sigara kullanımı & 328 & 32,0 \\
Evet & 696 & 68,0 \\
Hayır & 1024 & 100,0 \\
Toplam & & \\
\hline Sigara kullanım sıklığı & 251 & 76,0 \\
Her gün & 26 & 7,9 \\
Gün aşırı & 51 & 16,1 \\
Çok seyrek & 328 & 100,0 \\
Toplam & & \\
\hline Alkol kullanımı & 198 & 19,3 \\
Evet & 826 & 80,7 \\
Hayır & 1024 & 100,0 \\
Toplam & & \\
\hline Alkol kullanım sıklığı & 14 & 8,0 \\
Her gün & 29 & 14,5 \\
Gün aşırı & 155 & 77,5 \\
Çok seyrek & 198 & \\
Toplam & &
\end{tabular}

Gece yeme sendromu bakımından incelendiğinde çalışmaya katılan 1024 öğrenciden 676 (\%66) öğrencide gece yeme sendromu olduğu saptanmıştır. Gece yeme sendromu olmayan öğrenci sayısı ise 348 (\%34) olarak bulunmuştur. Gece yeme anketine göre GYS olan öğrencilerin aldığı toplam puan $28,87 \pm 3,06$ bulunurken, GYS olmayan öğrencilerin aldığı toplam puan $21,64 \pm 2,23$ olarak bulunmuştur. GYS olan ve olmayan öğrencilerin gece yeme anketinden aldıkları puanlar karşılaştıııldığında istatiksel olarak anlamlı bir fark bulunmuştur $(p<0,05)$ (Tablo 4$)$.

Tablo 4. Öğrencilerin gece yeme anketi puan ortalamaları

\begin{tabular}{lccc} 
GYS görülme durumu & Ortalama \pm SS & Min-Max & $\boldsymbol{P}$ \\
\hline GYS var & $28,87 \pm 3,06$ & $25-42$ & \\
GYS yok & $21,64 \pm 2,23$ & $13-24$ & $\leq 0,001^{*}$ \\
Toplam & $26,41 \pm 4,42$ & $13-42$ & \\
\hline
\end{tabular}

${ }^{*} p<0,01,{ }^{* *} p<0,05$

Gece yeme sendromu olan ve olmayan öğrencilerin tanımlayıcı özellikleri değerlendirildiğinde erkek öğrencilerin $\% 65,1^{\prime}$ inde, kı öğrencilerin \%67, 1 'inde GYS olduğu saptanmıştır. GYS olan ve olmayan öğrenciler cinsiyet bakımından incelendiğinde, GYS görülme sıklığı ve cinsiyet arasında istatiksel olarak anlamlı bir fark saptanmamıştır $(p>0,05)$. Birinci öğretimde ve ikinci öğretimde okuyan öğrencilerin \%66'sında GYS olduğu bulunmuştur. Öğretim türü ve GYS görülme sıklığı arasında istatiksel olarak anlamlı bir fark bulunmamıştır ( $p>0,05)$. GYS görülme sıklığının en fazla olduğu fakülteler ise Edebiyat, Havacılık ve Uzay Bilimleri, İletişim Fakültesi'dir. Fakülte farklıı̆̆ı ve GYS görülme sıklığı arasında istatiksel olarak anlamlı bir fark bulunmuştur $(p<0,05)$ (Tablo 5). Çalışmaya katılan öğrencilerin yaş ve antropometrik ölçümleri ile GYS görülme durumu değerlendirildiğinde istatiksel olarak anlamlı bir fark bulunmamıştır $(p>0,05)$.

Çalışmaya katılan öğrencilerin ve alkol kullanımlarına göre GYS görülme durumları incelendiğinde sigara kullanan öğrencilerin \%71,6'sında, alkol tüketen öğrencilerin ise $\% 69,5$ 'inde GYS olduğu saptanmıştır. Ancak sadece sigara kullanımı ve GYS görülme sıklığı arasında istatiksel olarak anlamlı bir fark bulunmuştur $(p<0,05)$ (Tablo 6).

\section{Tartışma}

Bireylerde yeme davranışı ve beden ağırlığı birçok faktörden etkilenmektedir. Insanlarda yeme davranışının oluşmasında sinir sistemindeki katekolaminerjik yollar ve fizyolojik reaksiyonlar önemli rol oynamaktadır (21). Yeme bozukluklarının ortaya çıkması ile birlikte beslenme yetersizliği, aşırı beslenme, depresyon, madde bağımlıı̆̆ı, anksiyete gibi ciddi sorunlar oluşabilmektedir (22). Yeme bozuklukları vakalarının \%90'dan fazlasını, 25 yaş altı bireyler oluşturmaktadır. Yeme bozukluğu açısından yüksek riskli gruplar ise; lise ve üniversite öğrencileridir. Üniversite öğrencileri içinde bulundukları yaş dönemi, psikolojik durum ve ekonomik zorlanmalar nedeniyle yeme bozuklukları için risk faktörlerini taşımaktadır. Üniversite öğrencileri şehir değişikliği nedeni ile ailesinden ayrılmakta olup; yurtlarda ve öğrenci evlerinde yaşamaya başlamaktadır. Şehir değişikliği nedeniyle üniversite öğrencilerinin yaşam biçimlerinde önemli değişiklikler meydana gelmektedir. Bu sebeplerden dolayı özellikle üniversite öğrencileri arasında yeme bozukluklarının görülme sıklığında artış olduğu görülmüştür (17). Çalışmaya yeme bozuklukları bakımından riskli grubu oluşturan üniversite öğrencileri dâhil edilerek, üniversite öğrencilerinde gece yeme sendromu ile cinsiyet ve öğretim türü arasındaki ilişki incelenmiştir.

Gece yeme sendromu ile ilgili literatür çalışmaları incelendiğinde ülkemizde üniversite öğrencilerinde gece yeme sendromu sıklığını araştıran sınırlı sayıda çalışma bulunmaktadır. Bu çalışmada araştırmaya katılan öğrencilerin yaş ortalaması $21,23 \pm 1,95$ olarak bulunmuş ve öğrencilerin \%54,3'ünü erkek, \%45,7'sini kız öğrenciler oluşturmuştur. Üniversite öğrencilerinde gece yeme sendromu 
Tablo 5. Öğrencilerin tanımlayıcı özelliklerine göre gece yeme sendromu görülme durumları

\begin{tabular}{|c|c|c|c|c|c|c|c|}
\hline \multirow[b]{3}{*}{ Tanımlayıcı özellikler } & \multicolumn{6}{|c|}{ GYS görülme durumu } & \multirow[b]{3}{*}{$P$} \\
\hline & \multicolumn{2}{|c|}{ GYS var } & \multicolumn{2}{|c|}{ GYS yok } & \multicolumn{2}{|c|}{ Toplam } & \\
\hline & Sayı (n) & Yüzde (\%) & Sayı (n) & Yüzde (\%) & Sayı (n) & Yüzde (\%) & \\
\hline \multicolumn{8}{|l|}{ Cinsiyet } \\
\hline Erkek & 362 & 65,1 & 194 & 34,9 & 556 & 100,0 & \multirow{2}{*}{0,509} \\
\hline Kadın & 314 & 67,1 & 154 & 32,9 & 468 & 100,0 & \\
\hline \multicolumn{8}{|l|}{ Fakülte } \\
\hline İktisadi ve İdari Bilimleri Fakültesi & 122 & 72,2 & 47 & 27,8 & 169 & 100,0 & \multirow{9}{*}{$\leq 0,001^{*}$} \\
\hline İlahiyat Fakültesi & 47 & 57,3 & 35 & 42,7 & 82 & 100,0 & \\
\hline Eğitim Fakültesi & 40 & 48,2 & 43 & 51,8 & 83 & 100,0 & \\
\hline İletişim Fakültesi & 55 & 73,3 & 20 & 26,7 & 72 & 100,0 & \\
\hline Fen Fakültesi & 29 & 72,5 & 11 & 27,5 & 40 & 100,0 & \\
\hline Edebiyat Fakültesi & 135 & 75,8 & 43 & 24,2 & 178 & 100,0 & \\
\hline Turizm Fakültesi & 8 & 72,7 & 3 & 27,3 & 11 & 100,0 & \\
\hline Havacılık ve Uzay Bilimleri Fakültesi & 15 & 75,0 & 5 & 25,0 & 20 & 100,0 & \\
\hline Mühendislik Fakültesi & 225 & 61,5 & 141 & 38,5 & 366 & 100,0 & \\
\hline \multicolumn{8}{|l|}{ Öğrenim türü } \\
\hline Birinci Öğretim & 408 & 66,0 & 210 & 34,0 & 618 & 100,0 & \multirow{2}{*}{0,999} \\
\hline İkinci Öğretim & 268 & 66,0 & 138 & 34,0 & 406 & 100,00 & \\
\hline
\end{tabular}

Tablo 6. Öğrencilerin sigara ve alkol kullanımlarına göre gece yeme sendromu görülme durumları

\section{GYS görülme durumu}

\begin{tabular}{|c|c|c|c|c|c|c|c|}
\hline \multirow[b]{2}{*}{ Sigara ve alkol kullanma durumu } & \multicolumn{2}{|c|}{ GYS var } & \multicolumn{2}{|c|}{ GYS yok } & \multicolumn{2}{|c|}{ Toplam } & \multirow[b]{2}{*}{$P$} \\
\hline & Sayı (n) & Yüzde (\%) & Sayı (n) & Yüzde (\%) & Sayı (n) & Yüzde (\%) & \\
\hline \multicolumn{8}{|l|}{ Sigara kullanımı } \\
\hline Evet & 235 & 71,6 & 93 & 28,4 & 328 & 100,0 & \multirow{2}{*}{0,009 * } \\
\hline Hayır & 441 & 63,4 & 255 & 36,6 & 696 & 100,0 & \\
\hline \multicolumn{8}{|l|}{ Alkol kullanımı } \\
\hline Evet & 138 & 69,5 & 60 & 30,5 & 198 & 100,0 & \multirow{2}{*}{0,245} \\
\hline Hayır & 538 & 65,2 & 288 & 34,8 & 826 & 100,0 & \\
\hline
\end{tabular}

ile ağılık, fiziksel aktivite, yeme alışkanlıkları, sigara içme durumu ve uyku düzeni arasındaki ilişkiyi araştıran başka bir çalışmada yaş ortalaması 20,6 $\pm 1,68$ yıl bulunurken, örneklemin \%21,8'ini erkek, \%78,2'sini kız öğrenciler oluşturmuştur (23). Bu çalışmada öğrencilerin yaş ortalaması diğer çalışma ile benzer bulunurken, cinsiyet dağılımlarında farklılık olduğu görülmüştür. Bu çalışmada öğrencilerin öğretim türü ve bölümleri sorgulanarak gece yeme sendromu arasındaki ilişki incelenmiştir. Literatürde gece yeme sendromu ve öğretim türü arasındaki ilişkiyi inceleyen başka bir çalışma bulunmamaktadır.
Çalışmaya katılan öğrencilerin BKì ortalaması 22,86 $\pm 3,40$ $\mathrm{kg} / \mathrm{m}^{2}$ olarak bulunmuştur. Runfola ve arkadaşlarının (24) yapmış olduğu çalışmada üniversite öğrencilerinde GYS görülme sıklığı araştırılmıştır. Çalışmada öğrencilerin BKI ortalaması $23,3 \pm 3,4 \mathrm{~kg} / \mathrm{m}^{2}$ olarak bulunmuştur. Çalışmada öğrencilerin BKI ortalamaları incelendiğinde diğer çalışma sonuçları ile benzer olduğu görülmüştür. Üniversite öğrencilerin de GYS sıklığını araştıran başka bir çalışmada ise 849 öğrencinin \%11,6'sının kilolu/obez olduğu görülmüştür (25). Çalışmaya katılan öğrencilerin sigara ve alkol tüketim durumları incelendiğinde; öğrencilerin \%32'sinin 
sigara kullandığı, \%19,3'ünün alkol tükettiği bulunmuştur. Yahia ve arkadaşlarının (23) yaptığı çalışmada ise üniversite öğrencilerinin \%1,21'sinin sigara içtiği bulunmuştur.

Gece yeme sendromu bakımından incelendiğinde çalışmaya katılan öğrencilerin \%66'sında gece yeme sendromu olduğu saptanmıştır. 413 öğrencinin katıldığı başka bir çalışmada hafif düzey GYS olanlar $\% 8,5$, orta düzey GYS olanlar $\% 2,7$, ağır düzey GYS olanlar $\% 1,2$ olarak bulunmuştur (23). 18-26 yaş arasındaki 1636 üniversite öğrencisinin katıldığı bir çalışmada GYS sıklığının \%4,2 olduğu görülmüştür (24). 8-10 yaş arası 395 çocuk ile yürütülen bir çalışmada ise GYS sıklığı çocuklarda \%0, çocukların annelerinde $\% 0,5$, babalarında $\% 0,3$ olarak bulunmuştur (26). He ve arkadaşlarının (25) yapmış olduğu çalışmada ise 909 üniversite öğrencisinde GYS görülme sıklığı \%2,8 olarak bulunmuştur. Gece yeme anketine göre GYS olan öğrencilerin aldığı toplam puan $28,87 \pm 3,06$ bulunurken, GYS olmayan öğrencilerin aldığı toplam puanın $21,64 \pm 2,23$ olduğu görülmüştür. Runfola ve arkadaşlarının (24) yapmış olduğu çalışmada gece yeme anketinden 25 ve üzeri puan alanlar örneklemin $\% 2$ 'sini, 30 ve üzeri puan alanlar $\% 0,5^{\prime}$ ini oluşturmuştur. He ve arkadaşlarının (25) yapmış olduğu çalışmada ise gece yeme anketinden 25 ve üzeri puan alanlar örneklemin $\% 2,8^{\prime}$ ini, 30 ve üzeri puan alanlar \%0,4'ünü oluşturmuştur. Bu araştırmada ise gece yeme anketinden 25 ve üzeri puan alanlar örneklemin \%33,8'ini, 30 ve üzeri puan alanlar \%23,9'unu oluşturmuştur.

Çalışmaya katılan öğrencilerin yaş, cinsiyet ve antropometrik ölçümleri ile GYS görülme sıklığı arasında istatiksel olarak anlamlı bir fark saptanmamıştır. Yapılan benzer çalışmalarda da GYS görülme durumu ile yaş, cinsiyet ve BKI arasında istatiksel olarak anlamlı bir fark bulunamamıştır (24, 26-28). Yapılan başka bir çalışmada gece yeme sendromu prevelansının genç yetişkinler (18-30 yaş) arasında en yüksek, 65 yaş üzeri bireylerde en düşük olduğu bulunmuştur; ancak BKi, cinsiyet ve etnik köken ile GYS arasında anlamlı bir ilişki olmadığı görülmüştür (15). He ve arkadaşlarının (25) yapmış olduğu çalışma GYS görülme olasılığının kadınlara göre erkeklerde daha yüksek olduğunu göstermiştir. Zwan ve arkadaşlarının (29) yaptığı

\section{Kaynaklar}

1. Orhan FÖ, Tuncel D. Gece Yeme Bozuklukları. Psikiyatride Güncel Yaklaşımlar 2009;1:132-54. http://www.cappsy.org/archives/vol1/ no2/cap_1_11.pdf

2. Stunkard AJ, Grace WJ, Wolf HG. The night-eating syndrome: pattern of food in take among certain obese patients. Am J Med 1955;19:7886. [CrossRef] çalışmada GYS ile vücut ağılığı arasında pozitif ilişki olduğu görülmüştür. Öztürk ve arkadaşlarının (30) yaptığı çalışmada GYS ile yaş ve obezite durumu arasında anlamlı ilişki bulunurken, yapılan başka bir çalışmada GYS ile BKi arasında anlamlı ilişki bulunmuştur (31).

Yapılan bu çalışmada sigara kullanımı ve GYS görülme sıklığı arasında istatiksel olarak anlamlı bir fark bulunurken, alkol tüketimi ile GYS görülme sıklığı arasında istatiksel olarak anlamlı bir fark bulunmamıştır. Küçükgöncü ve arkadaşlarının (31) yapmış olduğu çalışmada da benzer sonuçlar elde edilmiş olup, sigara kullanımı ile GYS görülme sıklığı arasında ilişki saptanmıştır. Ancak alkol tüketimi ile GYS görülme sıklığı arasında anlamlı bir ilişki bulunamamıştır. Yapılan başka çalışmalarda ise sigara kullanımı ile GYS görülme sıklığı arasında anlamlı bir ilişki saptanmamıştır $(23,24)$.

\section{Çalışmanın sınırlılıkları}

Tek merkezli yapılan ve üniversitesi öğrencilerinde gece yeme sendromu sıklığını ve gece yeme sendromu ile öğrenim türü ve cinsiyet arasındaki ilişkiyi araştıran bu çalışmada öğrencilerin uyku süresi ile psikolojik durumlarının sorgulanmaması çalışmanın sınırlılıklarını oluşturmaktadır.

\section{Sonuç ve öneriler}

Sonuç olarak bu araştırmada üniversite öğrencileri arasında gece yeme sendromu görülme sıklığının oldukça yüksek olduğu ortaya konmuştur. Görülme sıklığı özellikle genç bireyler arasında giderek artan yeme bozuklukları Dünya Sağlık Örgütü tarafından tıbbi olarak önem gerektiren durum olarak nitelendirilmektedir. Bu nedenle üniversite öğrencileri arasında gece yeme sendromu gibi yeme bozukluklarının görülme sıklığı saptanarak gerekli koruyucu ve tedavi edici önlemlerin alınması gerekmektedir. Ayrıca üniversite öğrencilerine sağlıklı beslenme alışkanlığı kazandırımalı, aile ve eğitimcilerin bilinçlendirilmesi için eğitimler düzenlenmelidir. Sağlık açısından önemli bir konu olması itibari ile gece yeme sendromu ile ilgili daha kapsamlı çalışmalar yapılmalıdır. 
6. Stunkard AJ, Allison KC, O'Reardon JP. The night eating syndrome: a progress report. Appetite 2005;45:182-6. [CrossRef]

7. Pinto TF, da Silva FGC, de Bruin VMS, de Bruin PFC. Night eating syndrome: How to treat it? Rev Assoc Med Bras 2016;62:701-7. [CrossRef]

8. Rand CSW, Macgregor A, Stunkard AJ. The night eating syndrome in the general population and among postoperative obesity surgery patients. Int J Eat Disord 1997;22:65-9. [CrossRef]

9. Hsu LK, Sullivan SP, Benotti PN. Eating disturbances and outcome of gastric bypass surgery: a pilot study. Int J Eat Disord 1997;21:385-90. [CrossRef]

10. Lundgren JD, Allison KC, Crow S, O'Reardon JP, Berg KC, Galbraith $\mathrm{J}$, et al. Prevalence of the night eating syndrome in a psychiatric population. Am J Psychiatry 2006;163:156-8. [CrossRef]

11. Allison KC, Crow SJ, Reeves RR, West DS, Foreyt JP, Dilillo VG, et al. The Eating Disorders Subgroup of the Look AHEAD Research Group. Binge eating disorder and night eating syndrome in adults with type 2 diabetes. Obesity 2007;15:1287-93. [CrossRef]

12. Olbrich K, Mühlhans B, Allison KC, Hahn EG, Schahin SP, de Zwaan $M$. Night eating, binge eating and related features in patients with obstructive sleep apnea syndrome. Eur Eating Disord Rev 2009;17:120-7. [CrossRef]

13. Antelmi E, Vinai P, Pizza F, Marcatelli $M$, Speciale M, Provini $F$. Nocturnal eating is part of the clinical spectrum of restless legs syndrome and an underestimated risk factor for increased body mass index. Sleep Med 2014;15:168-72. [CrossRef]

14. Marshall HM, Allison KC, O'Reardon JP, Birketvedt G, Stunkard AJ. Night eating syndrome among non obese persons. Int J Eat Disord 2004;35:217-22. [CrossRef]

15. Striegel-Moore RH, Franko DL, Thompson D, Affenito S, Kraemer $\mathrm{H}$. Night eating: Prevalence and demographic correlates. Obesity 2006;14:139-47. [CrossRef]

16. Ertan T. Psikiyatrik Bozuklukların Epidemiyolojisi, Türkiye'de Sık Karşılaşılan Psikiyatrik Hastalıklar Sempozyum Dizisi; 2008. No: 62. ss.25-30.

17. Oğur S, Aksoy A, Selen H. Üniversite Öğrencilerinin Yeme Davranışı Bozukluğuna Yatkınlıkları: Bitlis Eren Üniversitesi Örneği. BEÜ Fen Bilimleri Derg 2016;5:14-26. [CrossRef]

18. Allison KC, Lundgren JD, O'Reardon JP, Martino NS, Sarwer DB, Wadden TA, et al. The Night Eating Questionnaire (NEQ): Psychometric pro-perties of a measure of severity of the Night Eating Syndrome. Eat Behav 2008;9:62-72. [CrossRef]

19. Atasoy N, Saraçlı Ö, Konuk N, Ankaralı H, Güriz SO, Akdemir A, et al. The reliability and validity of Turkish version of the Night Eating Questionnaire in psychiatric outpatient population [in Turkish]. Anatolian J Psychiatry 2014;15:238-47. [CrossRef]
20. Peker M, Oztora S, Caylan A, Dagdeviren HN. Internal Reliability of Turkish Version of "Night Eating Questionnaire" in General Adult Population. Euras J Fam Med 2016;5:109-12.

21. Balcıoğlu I, Başer SZ. Obezitenin Psikiyatrik Yönü. Türkiye'de Sık Karşılaşılan Psikiyatrik Hastalıklar. İ. Ü. Cerrahpaşa Tıp Fakültesi Sürekli Tıp Eğitimi Etkinlikleri 2008;62:341-8. https://docplayer.biz. tr/10558169-Obezitenin-psikiyatrik-yonu.html

22. Ulaş B, Uncu F, Üner S. Sağlık Yüksekokulu Öğrencilerinde Olası Yeme Bozukluğu Sıklığı ve Etkileyen Faktörler. İnönü Üniversitesi Sağlık Bilimleri Derg 2013;2:15-22. http://openaccess.inonu. edu.tr:8080/xmlui/bitstream/handle/11616/4841/makale. pdf? sequence $=1$ \&isAllowed $=y$

23. Yahia N, Brown C, Potter S, Szymanski H, Smith K, Pringle L, et al. Night eating syndrome and its association with weight status, physical activity, eating habits, smoking status, and sleep patterns among college students. Eat Weight Disord 2017;22:421-33. [CrossRef]

24. Runfola CD, Allison KC, Hardy KK, Lock J, Peebles R. Prevalence and clinical significance of night eating syndrome in university students. J Adolesc Health 2014;55:41-8. [CrossRef]

25. He J, Huang F, Yan J, Wu W, Cai Z, Fan X. Prevalence, demographic correlates, and association with psychological distress of night eating syndrome among Chinese college students. Psychol Health Med 2018;23:578-84. [CrossRef]

26. Lundgren JD, Drapeau V, Allison KC, Gallant AR, Tremblay A, Lambert $M A$, et al. Prevalence and Familial Patterns of Night Eating in the Québec Adipose and Lifestyle InvesTigation in Youth (QUALITY) Study. Behav Psychol 2012;20:1598-603. [CrossRef]

27. Cengiz Y, Toker SG, Karamustafalığlu KO, Bakım B, Özçelik B. Psikiyatrik Ayaktan Hasta Popülasyonunda Gece Yeme Sendromunun Yaygınlığı ve Diğer Psikiyatrik Bozukluklarla Birlikteliği. New Symp J 2011;49:83-8. http://yenisymposium.com/Pdf/TR-YeniSempozyumb91df975.PDF

28. Civil Arslan F, Tiryaki A, Sağlam Aykut D, Özkorumak E, Çalışkan illter Z, Günaydın D. Ağır Ruhsal Bozukluğu Olan Kilolu veya Obez Ayaktan Hasta Grubunda Gece Yeme Sendromu Yaygınlığı. Türk Psikiyatri Derg 2015;26:242-8. http://www.turkpsikiyatri.com/PDF/ C26S4/03.pdf

29. Zwaan M, Müller A, Allison KC, Brahler E, Hilbert A. Prevalence and Correlates of Night Eating in the German General Population. Plos One 2014;9:e97667. [CrossRef]

30. Öztürk GZ, Eğici MT, Toprak D, Erdoğan AM. Relationship Between Night Eating Disorders and Obesity. Ankara Med J 2018;:117-22. [CrossRef]

31. Küçükgöncü S, Beştepe E. Majör Depresyon ve Anksiyete Bozukluğu Hastalarında Gece Yeme Sendromu. Nöropsikiyatri Arşivi 2014;51:368-75. [CrossRef] 